\title{
Morbidity and mortality of iatrogenic hemothorax occurring in a cohort of liver transplantation recipients: a multicenter observational study
}

\author{
Fabrizio Panaro ${ }^{1,13}$ (1) $\cdot$ Bader Al Taweel ${ }^{1} \cdot$ Piera Leon $^{1} \cdot$ Davide Ghinolf $^{2}$ - Giuliano Testa ${ }^{3} \cdot$ Marit Kalisvaart $^{4}$. \\ Paolo Muiesan ${ }^{4} \cdot$ Renato Romagnoli $^{5} \cdot$ Mickael Lesurtel $^{6} \cdot$ Gianluca Cassese $^{7} \cdot$ Stephanie Truant $^{8} \cdot$ Pietro Addeo $^{9}$. \\ Mauricio Sainz-Barrica ${ }^{10}$. Umberto Baccarani ${ }^{11}$. Paolo De Simone . Fouad Belafia $^{12}$. Astrid Herrero ${ }^{1}$. \\ Francis Navarro ${ }^{1}$
}

Received: 10 April 2021 / Accepted: 19 May 2021 / Published online: 3 July 2021

(c) Italian Society of Surgery (SIC) 2021

\begin{abstract}
Hemothorax (HT) is a life-threatening condition, mainly iatrogenic and poorly explored in Liver Transplantation (LT) recipients. The aim of this study is to report and analyze for the first time incidence and outcomes of HT in LT recipients, as well as to suggest a management strategy. Data concerning 7130 consecutive adult liver and liver-kidney transplant recipients were retrospectively collected from ten Transplantation Centers' institutional databases, over a 10-year period. Clinical parameters, management strategies and survival data about post-operative HT were analyzed and reported. Thirty patients developed HT during hospitalization (0.42\%). Thoracentesis was found to be the most common cause of HT (16 patients). A non-surgical management was performed in 17 patients, while 13 patients underwent surgery. 19 patients developed thoracic complications after HT treatment, with an overall mortality rate of 50\%. The median length of stay in Intensive Care Units was 22 days $\left(\mathrm{IQR}_{25-75} 5-66.5\right)$. Postoperative hemothorax is mainly due to iatrogenic causes in LT recipients. Despite rare, it represents a serious complication with a high mortality rate and a challenging medical and surgical management. Its occurrence should always be prevented.
\end{abstract}

Keywords Liver transplantation $\cdot$ Liver transplant recipients $\cdot$ Hemothorax $\cdot$ Thoracic surgery

Fabrizio Panaro

f-panaro@chu-montpellier.fr

1 Division of Digestive Surgery and Transplantation, Department of Surgery, Montpellier University Hospital, 34070 Montpellier, France

2 Division of Transplantation, Department of Surgery, Pisa University Hospital, Pisa, Italy

3 Liver Transplantation Unit, Department of Surgery, Baylor University Hospital, Dallas, TX, USA

4 Liver Unit, Queen Elizabeth Hospital, Birmingham, UK

5 Liver Transplantation Unit, Department of Surgery, Turin University Hospital, Turin, Italy

6 Division of Liver Transplantation, Department of Surgery, Lyon University Hospital, Lyon, France

7 HPB Surgery Unit, Department of Clinical Medicine and Surgery, Federico II University, Naples, Italy
8 Division of Transplantation, Department of Surgery, Lille University Hospital, Lille, France

9 Department of Surgery, HPB Surgery and Liver Transplantation, Hôpital de Hautepierre, University Hospital, Strasbourg, France

10 Division of Transplantation, Department of Surgery, Leuven University Hospital, Leuven, Belgium

11 Division of Transplantation, Department of Surgery, Udine University Hospital, Udine, Italy

12 Department of ICU, Montpellier University Hospital, 34070 Montpellier, France

13 Division of HBP Surgery and Transplantation, Department of Surgery, St. Eloi Hospital, Montpellier University Hospital-School of Medicine, 80 Avenue Augustin Fliche, 34090 Montpellier, France 


\section{Introduction}

Liver transplantation (LT) is increasingly performed worldwide over the lasts 5 decades to treat end-stage liver disease. Despite the improvements in the field of immunosuppression and clinical management, the rate of postoperative complications after LT is still high $[1,2]$. The most common post-operative thoracic complication after LT is pleural effusion [3]. The incidence of pleural effusion stands between 32 and $47 \%$ and can be due to subdiaphragmatic surgery, to central vein (jugular, subclavian) line (CVL) insertion or to percutaneous liver biopsy (PLB). In $22-52 \%$ of the cases a chest drainage (CT) is required, with the risk of complications like pneumothorax and hemothorax [3, 4]. Moreover, LT recipients could suffer from persistent coagulopathy because of an impaired production of coagulation factors, as well as low platelets number (LPN) and/or thrombopathy. Persistent coagulopathy in LT recipients is probably secondary to previous cirrhosis status, hypersplenism, and/or a delayed graft function. The risk for hemothorax (HT) is then higher than general population. Clinicians must be aware of such a complication, to best prevent it and to make a timely diagnosis and treatment.

The aim of this observational international study was to report causes and incidence of HT and to discuss the strategies to manage this rare but life-threatening condition in LT recipients.

\section{Methods}

\section{Study design and data sources}

This is a multicenter observational retrospective study. Data regarding consecutive adult LT recipients undergoing single liver transplantation or liver-kidney transplantation between 1st January 2009 and 31 December 2019 were retrospectively collected from the institutional databases of ten International Transplant Units. Data regarded patient's demographics, diagnosis (hemothorax) and procedures (thoracentesis, percutaneous liver biopsy, thoracotomy, thoracoscopy, intercostal embolization) according to the International Classification of Diseases (ICD-10), hospitality status and length of hospital stay. Data regarding the management of HT, coagulation tests, Child-Turgot-Pugh score, MELD score, morbidity and mortality were also recorded. Patients younger than 18 years, patients with genetic coagulopathies, recipients receiving combined liver-lung or liver-heart transplantations and patients receiving organs from living donors were excluded from the study.
The study was approved by the local Institutional Review Board (IRB \#2019-01-234) and reporting was made according to STROCCS guidelines [5].

\section{Definitions}

Diagnosis of HT was clinical in patients who already has a chest tube (CT) or radiological with computed tomography (CT) scan.

Type of treatment provided, beyond medical resuscitation, was defined "non-surgical" when CT/US-guided percutaneous procedures and/or radiologic embolization (RE) were performed.

\section{Statistical analysis}

Continuous data are expressed as mean and standard deviation (SD) or median and interquartile range (IQR) depending on whether or not they have a normal distribution. Categorical data are expressed as frequencies and associated percentages. All survival analyses were performed using Kaplan-Meier to compute median and 95\% CI. Median follow-up was calculated using reverse Kaplan-Meier methodology. The statistical analysis has been conducted using the SPSS software (version 26.0).

\section{Results}

\section{Patients' characteristics}

A total of 7130 consecutive adult LT recipients from ten Transplantation Units over a 10-year period met the inclusion criteria. All the patients had undergone CVL insertion, while 598 patients $(8.3 \%$ ) had undergone PLB, before or during LT. $2852(40 \%)$ patients developed a pleural effusion after LT, and $1053(14,8 \%)$ underwent thoracentesis.

30 patients meeting inclusion criteria developed HT after LT and were further analyzed, accounting for overall incidence of $0.42 \%$. Mean age of patients with HT was 48.5 years (range 18-67). Mean Child-Pugh score was B9 (range A6-C13) and mean MELD score was 22 (range 6-40). Indications for LT in these 30 patients were alcoholic cirrhosis $(\mathrm{n}=8)$, hepatitis $\mathrm{C}$ virus $(n=5)$, hepatocellular carcinoma (HCC) $(n=4)$, echinococcosis $(n=2)$, nonalcoholic steatohepatitis (NASH) $(n=2)$, polycystic disease $(n=2)$ and other single miscellaneous cases. It was the second LT in four patients, while in one case it was the third LT. 12 patients had previous respiratory disorders before LT (5 heavy smokers, 3 hydrothorax, 1 pulmonary hypertension, 1 emphysema and 2 mild pleural effusions), but none of them underwent thoracic surgery or thoracentesis before transplantation. 
3 patients had anticoagulation therapy, 5 anti-platelets therapy and 12 had both anticoagulant and anti-platelet therapy. Prior to HT, the mean prothrombin time (PT) was $70.2 \%( \pm 22.6)$ and mean platelets count was of $121.000 \mathrm{plt} /$ $\mathrm{mm}^{3}( \pm 18.998)$. In particular, platelet count was $<50,000$ in 4 patients (13.3\%).

All features of patients with HT are detailed in Table 1.

Table 1 Patients' characteristics

\begin{tabular}{|c|c|}
\hline Characteristics & $\begin{array}{l}\text { Patients with } \\
\text { HT post LT } \\
N=30\end{array}$ \\
\hline Age, mean (range), yrs & $48,5(16-66)$ \\
\hline Gender (M/F), $n(\%)$ & $18(60) / 12(40)$ \\
\hline BMI, Median (range) & $24.4(18-31.5)$ \\
\hline \multicolumn{2}{|l|}{ Number of LT, $n(\%)$} \\
\hline Primary LT & $25(83.3)$ \\
\hline Secondary LT & 4 \\
\hline Third LT & 1 \\
\hline \multicolumn{2}{|l|}{ Main indication for LT, $n(\%)$} \\
\hline Alcohol & $8(26,67)$ \\
\hline $\mathrm{HCV}$ & $5(16,7)$ \\
\hline $\mathrm{HCC}$ & $5(16,7)$ \\
\hline NASH & $2(6,6)$ \\
\hline Polycystic hepatic disease & $2(6,6)$ \\
\hline Echinococcosis & $2(6,6)$ \\
\hline HBV & $1(3,3)$ \\
\hline Autoimmune hepatitis & $1(3,3)$ \\
\hline Hyperoxaluria & $1(3,3)$ \\
\hline Fulminant hepatic failure & $1(3,3)$ \\
\hline Primary sclerosing cholangitis & $1(3,3)$ \\
\hline Primary non function & $1(3,3)$ \\
\hline \multicolumn{2}{|l|}{ Scores } \\
\hline Child-Pugh score, mean (range) & $9(6-13)$ \\
\hline MELD score, mean (range) & $22(6-40)$ \\
\hline Respiratory past history, $n(\%)$ & $12(40)$ \\
\hline Heavy smoker & 4 \\
\hline Hydrothorax & 3 \\
\hline Pulmonary hypertension & 1 \\
\hline Emphysema & 1 \\
\hline Recurrent hemoptysis & 1 \\
\hline Mild pleural effusion & 1 \\
\hline Prior thoracic surgery & 0 \\
\hline Thoracentesis & 0 \\
\hline Anticoagulant or anti-platelet drugs before LT & 13 \\
\hline Post-LT pleural effusion, $n(\%)$ & $2852(40)$ \\
\hline Donor age yrs, Mean (range) & $69(56-89)$ \\
\hline
\end{tabular}

$M$ male, $F$ female, $L T$ liver transplantation, $H T$ hemothorax, $B M I$ body mass index, $H C C$ hepato cellular carcinoma, $N A S H$ nonalcoholic steato-hepatitits, $H C V$ hepatitis $\mathrm{C}$ virus, $H B V$ hepatitis $\mathrm{B}$ virus, $n$ number, $y r s$ years

\section{Causes and timing of HT occurrence}

Thoracentesis, even if performed under ultrasound guidance (US) in $62 \%$ of the cases, represented the most common cause of HT (53.3\% of the patients). Specifically, in the thoracentesis subgroup, incidence of HT was as high as $1.52 \%(16 / 1053)$. Liver biopsy was responsible for HT in 6 patients $(20 \%)$, with an incidence of $1 \%$ on this procedure, while CVL insertion accounted for other 3 patients $(10 \%$, with an incidence of $0.04 \%)$. Moreover, HT was consequent to diaphragmatic resection performed during $\mathrm{LT}$ in 1 patient and to percutaneous trans-hepatic cholangiography in another one. No evident cause of HT was detected in 3 patients (Fig. 1). The median delay between LT and HT apparition was of 12 days.

\section{HT management}

Anticoagulation therapy and anti-platelet drugs was always discontinued and antagonized if possible. Fluid resuscitation was immediately provided. A total of $25(83.3 \%)$ patients received blood transfusions. Mean red blood cells (RBC) units transfused was $5.68( \pm 2.6)$. A percutaneous 24- or 26-French CT was inserted in $25(83.3 \%)$ patients to decompress pleural cavity and to monitor bleeding. Platelets transfusion was provided before thoracentesis when platelets count was less than 50,000 .

In 17 patients $(56.67 \%)$ a non-surgical treatment was provided: 13 (43.3\%) patients needed CT placement only, $2(6.67 \%)$ patients required CT and an intercostal arterial

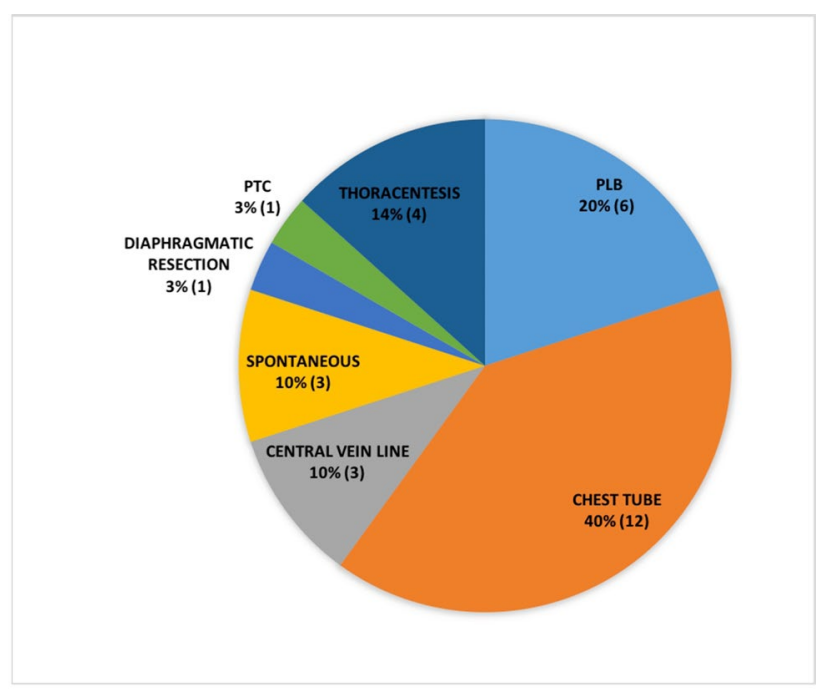

LT: liver transplantation; PLB: percutaneous liver biopsy; PTC: percutaneous trans-hepatic cholangiography; Spontaneous (or undetermined)

Fig. 1 Causes of the hemothorax. $L T$ liver transplantation, $P L B$ percutaneous liver biopsy, PTC percutaneous trans-hepatic cholangiography; Spontaneous (or undetermined) 
embolization and $2(6.67 \%)$ patients benefited from an arterial intercostal embolization with no CT.

Surgical treatment was reserved to $13(43.3 \%)$ patients: $10(33.3 \%)$ patients had thoracotomy and in $3(10 \%)$ patients had three-port thoracoscopy for exploration. No « thoracic packing» had to be performed. For more information on HT, see Table 2.

Management strategies provided are resumed in Fig. 2.

\section{Short and long-term outcomes of HT treatment}

Nineteen patients (63.3\%) developed thoracic complications after HT treatment: 8 (26.67\%) patients had an acute respiratory distress syndrome (ARDS), 6 (20\%) patients needed prolonged mechanical ventilation support, 2 (6.67\%) patients presented a pleural abscess, one patient had a severe cardio-respiratory shock, another one a retained HT and one patient had a residual pleural effusion treated medically. The median length of the ICU hospital stay was of 17 days $\left(\mathrm{IQR}_{25-75}\right.$ 7.5-35.5). Data on morbidity and mortality are summarized in Table 3. We report a mean interval between diagnosis of HT and surgery, when indicated, of $6 \mathrm{~h}$ (ranging from 1 to 32 ). No significant differences in morbidity

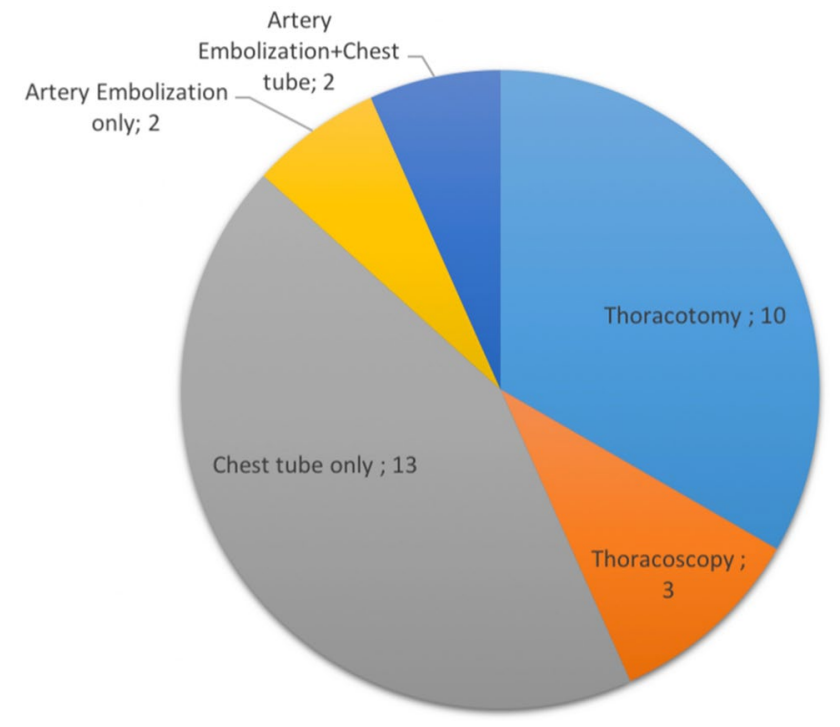

Fig. 2 Performed treatments

and mortality rates were detected in patients who received non-surgical treatment compared to the surgical one. The overall mortality rate was $50 \%(n=15)$, after a median
Table 2 Features of the hemothorax

\begin{tabular}{ll}
\hline Characteristics & $\begin{array}{l}\text { Patients with HT } \\
\text { post LT } N=30\end{array}$ \\
\hline Simultaneous pneumothorax, $n(\%)$ & $20(66.7)$ \\
Side of the hemothorax, $n(\%)$ & $21(70)$ \\
Right & 9 \\
Left & $20(66.7)$ \\
Anti-coagulations/platelets drugs after LT, $n(\%)$ & 3 \\
Anticoagulation only & 5 \\
Antiplatelet only & 12 \\
Anticoagulation + antiplatelet & \\
Hemostase Biologic parameters the day of HT & $70,2(22,6)$ \\
PT (\%), Mean (range) & $121,000(18.998)^{\mathrm{a}}$ \\
Platelets count plt/mm ${ }^{3}$, mean $(\mathrm{SD})$ & 9 \\
$<70,000$ plt/mm ${ }^{3}$ & 4 \\
$<50,000$ plt/mm ${ }^{3}$ & \\
Transfusion & $25(83.3)$ \\
Number of patients transfused, $n(\%)$ & $6(0-17)$ \\
RBC units, median (range) & \\
Management of HT & $175(1-3232)$ \\
Delay between HT and LT, Median days, (range) & $18(60)$ \\
$<30$ days after LT, $\mathrm{n}$ patients $(\%)$ & $25(83.3)$ \\
Initially percutaneous chest tube treatment, $n(\%)$ & $12(40)$ \\
Use of guided echography, $n(\%)$ & $13(43.3)$ \\
Surgical treatment, $n(\%)$ & $6(1-32)$ \\
Delay between chest-tube and surgery (h) median (range) & \\
\hline
\end{tabular}

$P T$ prothrombine time, $R B C$ red blood cell, $n$ number, $h$ hours

${ }^{\mathrm{a}}$ These number before platelet transfusion 
Table 3 Outcomes after hemothorax treatment

\begin{tabular}{ll}
\hline Characteristics & $\begin{array}{l}\text { Patients with } \\
\text { HT post LT } \\
N=30\end{array}$ \\
\hline Median follow-up, months $\left(\mathrm{IQR}_{25-75}\right)$ & $42(12-180)$ \\
Thoracic complications, $n(\%)$ & $19(63.3)$ \\
ARDS & 8 \\
Prolonged mechanical ventilation & 6 \\
Pleural abscess & 2 \\
Residual uninfected pleural effusion & 1 \\
Retained hemothorax & 1 \\
Cardio-respiratory shock & 1 \\
ICU hospital stay (days), median $\left(\mathrm{IQR}_{25-75}\right)$ & $12(5-66.5)$ \\
Survival rate, $n$ (\%) & $15(50)$ \\
\hline
\end{tabular}

ARDS acute respiratory distress syndrome, Clavien-Dindo classification: $(I V-A)$ life-threatening complication requiring IC/ICU management (single organ dysfunction); $(V)$ death of a patient

follow-up of 42 months. The median Overall Survival (OS) was 28.5 months (Fig. 3).

\section{Discussion}

The most common postoperative pulmonary complication following LT is pleural effusion, with a reported incidence between 32 and 47\%. Pleural effusion after LT, most commonly identified unilaterally on the right side, is known to be associated with a poorer short-term outcomes, with a the need for thoracentesis varies between 22 and 52\% in literature [3]. Similarly, in our series, $14.8 \%$ of the patients undergoing LT had a CT in the post-transplant period $(n=1055)$.
CT placement is not risk free and its benefits must be balanced against possible complications. The most common and frightened complications of the procedure, as well as CVL insertion or PBL, are pneumothorax and hemothorax. In cirrhotic patients, the reported incidence of pneumothorax is $8.4 \%$ and $0-2 \%$ for HT $[6,7]$. Currently, no study addressing the same issue for $\mathrm{LT}$ recipients is available in literature.

In our cohort of LT recipients, the overall incidence of HT was of $0.42 \%$. In the thoracentesis subgroup, incidence of HT was as high as $1.52 \%(16 / 1053)$. Fortunately, the risk of HT due to thoracentesis is low even in critically ill patients. In the meta-analysis by Gordon et al., there have been 6 cases reported among 6605 procedures performed [8]. Based on our analysis, HT is still a rare and very severe complication event after thoracentesis in LT recipients. Mortality accounted for as much as $50 \%$ of the patients.

Due to its rarity and its severe features, HT management is still debated and no recommendations have been reported, at the time. Moreover, major difficulty in our specific population was the presence in some of the patients of a persistent coagulopathy and/or residual portal hypertension's signs (low PT, low platelet count). This happens in the early posttransplant period when a delayed graft function occurs [9]. A delayed graft function recovery is more frequent when marginal liver donors are used [10]. Interestingly, in our cohort, the mean donor age was 69 years and mean BMI was 27.9.

Currently, no optimization of coagulation is recommended before $\mathrm{CT}$ insertion and drainage of non-urgent cases should be avoided if international normalization ratio (INR) is $>1.5$ [11]. Urgent cases could be managed with the administration of fresh frozen plasma and platelet concentrates when invasive interventions are necessary. Pulchalski et al. also suggested that thoracentesis may be
Fig. 3 Flowchart for an intercostal procedure (thoracentesis, biliary drainage, liver biopsy) in LT recipients. CTS computer tomography scan, $U S$ ultrasound, $H b$ hemoglobin level, $L T$ liver transplantation, $P T L$ platelet count, $P T(\%)$ prothrombin time

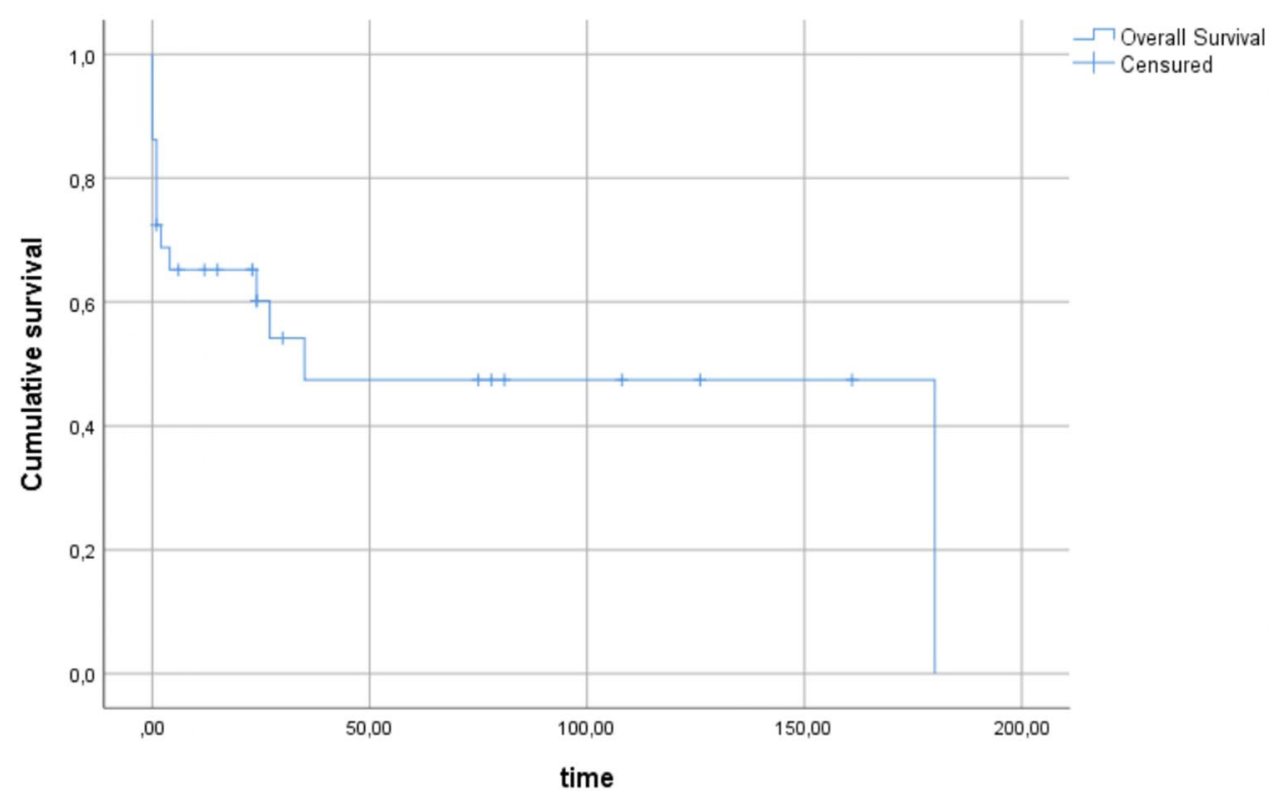


safely performed without prior correction of coagulopathy, thrombocytopenia, or medication-induced bleeding risk [12]. Anyway, all these series did not consider the particular population of LT recipients who can develop hemorrhagic complications even with subnormal coagulation parameters. In fact patients that developed HT in our series had a mean PT of 77\% ( \pm 22.6$)$ and a mean platelet count of 121,000 $( \pm 18.998)$. Thus, it's very important to make any possible effort to detect coagulopathy and thrombopaty, as well as try to meticulously improve coagulation before any invasive intervention on LT patients.

Few studies analyzing the complications due to invasive procedures in the LT patient are available. Filingeri et al. reported 2 cases of pneumothorax and one case $(0.12 \%)$ of HT after 847 percutaneous liver biopsies performed with intercostal approach in LT recipients [13]. Pérez Roldán et al. reported $4(0.9 \%)$ cases of HT over 438 PLB: two patients required thoracotomy and mortality rate was as high as $25 \%$ [14]. Moreover, Jankovic et al. reported a fatal case of HT following CVL insertion [15].

We did not identify the origin of HT in $3(10 \%)$ of our patients after LT. In these undetermined cases, various causes more or less rare could be mentioned.

In addition to coagulopathy attention and optimization, performing the CT insertion under ultrasound (US) guide is safer, to avoid the risk of HT $[4,11,16]$. Miraglia et al. recommends ultrasound-guided placement of pigtail catheters in supine position for pleural effusion [17]. As high as $40 \%$ (12 patients) of our population had CT placement using anatomical landmarks and no US guide, since our study has an inclusion period that started partially before the publication of International Recommendations on thoracentesis [11]. Surely, the CT insertion in Intensive Care Unit (ICU) and in dorsal position under US guide is safer and is integrated in our practice as standard after 2015 .

No studies focused yet on intercostal artery embolization to stop chest bleeding in LT recipients. We think that radiologic embolization could be very useful in same cases and highly effective. It should be considered as a valuable tool in the therapeutic arsenal for non-catastrophic HT (slow but persistent bleeding with no hemodynamic compromise) when available.

According to previous publications [18-20], we designed a protocol to reduce the risk of HT during an intercostal invasive procedure (thoracentesis, biliary drainage, liver biopsy) in LT recipient (see Fig. 4). We designed also a flowchart resuming our management of HT when it occurs in LT patients (see Fig. 5). The management of the HT starts generally with CT placement. Depending on patient's hemodynamic and amount of bleeding, CT clamping is not recommended [21, 22]. Bauman et al. reported that the size of CT "does not matter": in his study, in fact, pigtail catheters is as effective as bigger chest tubes in the management of HT [23].

When medical support, blood transfusion and chest decompression allow stabilization of the patient's general conditions, radiologic embolization could be considered if bleeding is persistent. Otherwise, when all these tools are inadequate to stabilize patient's hemodynamic, surgery is indicated, with no delay. It is difficult to compare all cases and to homogenize to the same attitude all time because of different patients, past histories, comorbidities, amount of bleeding and availability of therapeutic tools. However, we can conclude that an aggressive strategy should not be delayed if appropriated, given the vulnerability LT recipient patients (taking into account for coagulopathy, portal hypertension, deficient nutrition status compared to a nontransplant population).

Given that immunosuppression therapy, moreover, the risk of bacterial infection is increased in LT recipients [24]. When HT is abundant but stable, thoracoscopy should be performed if signs of infection appear, without latency. The pleural cavity has to be well cleaned up, as well as for non-transplanted patients. The lower impact on respiratory parameters of thoracoscopy compared to thoracotomy must be considered [25-28].
Fig. 4 Flowchart of the management in case of a suspected HT (hemothorax) in our LT recipients. $H b$ hemoglobin level, VATS video assisted thoracoscopy

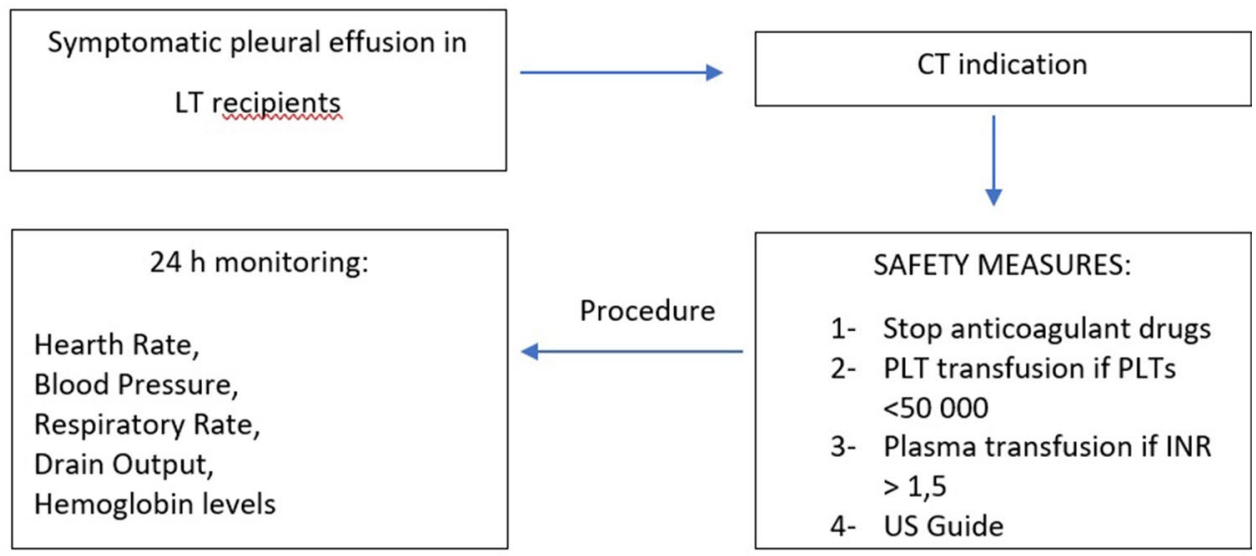


Fig. 5 Cumulative survival of LT recipient with HT

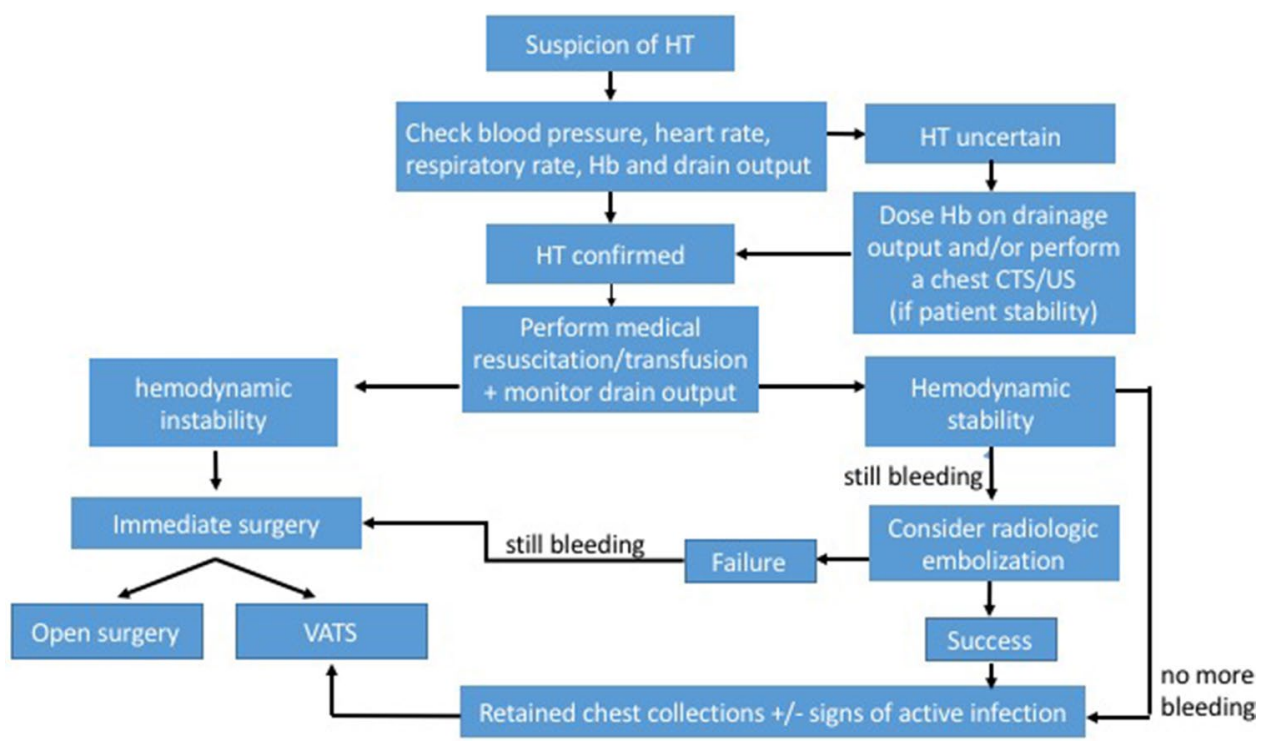

Pleural fibrinolytic therapy, suggested by Kumaret al. [29] is probably less safe than thoracoscopy in LT recipients because of uncontrolled bleeding risks. However, series are needed to confirm this statement. In any case, we do not advise this type of treatment in LT recipients.

This study has several limitations. First of all its retrospective design and t. Second, data are heterogeneous because of different attitudes and management strategies in different surgical centers.

On the other side, HT is a very rare and fatal complication and literature about it and its management in LT recipients is really limited.

In conclusion, postoperative hemothorax is due mainly to iatrogenic causes in LT recipients. Despite rare, it brings high morbidity and mortality rates. All efforts must be done to prevent this dramatic complication, paying particular attention to coagulation asset and using US guide for all invasive maneuvers. Management is challenging, medical and interventional tools as CT, RE and surgery are valuables tools available. Thoracoscopy should be preferred when surgery is mandatory.

Author contributions FP: design, data manager, drafting, final approval. BA: design, data manager, drafting, final approval. PL: design, data manager, drafting, final approval. DG: design, data manager, drafting, final approval. GT: data manager, drafting, final approval. MK: data manager, drafting, final approval. PM: data manager, drafting, final approval. RR: data manager, drafting, final approval. GC: data manager, drafting, final approval. ML: data manager, drafting, final approval. ST: data manager, drafting, final approval. PA: data manager, drafting, final approval. MS-B: data manager, drafting, final approval. UB: data manager, drafting, final approval. PDS: data manager, drafting, final approval. FB: design, drafting, final approval. AH: data manager, design, drafting. FN: design, drafting, final approval.
Funding The authors received no specific funding for this work.

Availability of data and materials Data are available upon request to the corresponding author.

\section{Declarations}

Conflicts Of Interest The authors declare no conflicts of interest.

Research involving human participants and/or animals The study is a retrospective research from institutional database. The Istitutional review board number has been inserted (IRB à2019-01-234).

\section{References}

1. Adam R, Karam V, Cailliez V et al (2018) Annual Report of the European Liver Transplant Registry (ELTR) - 50-year evolution of liver transplantation. Transpl Int. https://doi.org/10.1111/tri. 13358

2. Adam R, Karam V, Delvart V et al (2012) Evolution of indications and results of liver transplantation in Europe A report from the European Liver Transplant Registry (ELTR). J Hepatol. https:// doi.org/10.1016/j.jhep.2012.04.015

3. Wiering L, Sponholz F, Brandl A et al (2020) Perioperative pleural drainage in liver transplantation: a retrospective analysis from a high-volume liver transplant center. Ann Transplant. https://doi. org/10.12659/AOT.918456

4. Cantey EP, Walter JM, Corbridge T, Barsuk JH (2016) Complications of thoracentesis: incidence, risk factors, and strategies for prevention. Curr Opin Pulm Med. https://doi.org/10.1097/MCP. 0000000000000285

5. Agha R, Abdall-Razak A, Crossley E, Dowlut N, Iosifidis C, Mathew GSTROCSS (2019) Guideline: Strengthening the reporting of cohort studies in surgery. Int J Surg. https://doi.org/10. 1016/j.ijsu.2019.11.002

6. Lazaridis KN, Frank JW, Krowka MJ, Kamath PS (1999) Hepatic hydrothorax: Pathogenesis, diagnosis, and management. Am J Med. https://doi.org/10.1016/S0002-9343(99)00217-X 
7. Alonso JC (2010) Pleural effusion in liver disease. Semin Respir Crit Care Med. https://doi.org/10.1055/s-0030-1269829

8. Gordon CE, Feller-Kopman D, Balk EM, Smetana GW (2010) Pneumothorax following thoracentesis: a systematic review and meta-analysis. Arch Intern Med. https://doi.org/10.1001/archi nternmed.2009.548

9. Unger LW, Berlakovich GA, Trauner M, Reiberger T (2018) Management of portal hypertension before and after liver transplantation. Liver Transplant. https://doi.org/10.1002/lt.24830

10. Chen XB, Xu MQ (2014) Primary graft dysfunction after liver transplantation. Hepatobiliary Pancreat Dis Int. https://doi.org/ 10.1016/S1499-3872(14)60023-0

11. Brass P, Hellmich M, Kolodziej L, Schick G, Smith AF (2015) Ultrasound guidance versus anatomical landmarks for subclavian or femoral vein catheterization. Cochrane Database Syst Rev. https://doi.org/10.1002/14651858.CD011447

12. Puchalski JT, Argento AC, Murphy TE, Araujo KLB, Pisani MA (2013) The safety of thoracentesis in patients with uncorrected bleeding risk. Ann Am Thorac Soc. https://doi.org/10.1513/Annal sATS.201210-0880C

13. Filingeri V, Sforza D, Tisone G (2015) Complications and risk factors of a large series of percutaneous liver biopsies in patients with liver transplantation or liver disease. Eur Rev Med Pharmacol Sci 19(9):1621-9.

14. Pérez Roldán F, Bañares R, Clemente G et al (1995) Severe complications of percutaneous hepatic biopsy in patients with orthotopic liver transplantation. Gastroenterol Hepatol Oct;18(8):410-2.

15. Jankovic Z, Boon A, Prasad R (2005) Fatal haemothorax following large-bore percutaneous cannulation before liver transplantation. Br J Anaesth. https://doi.org/10.1093/bja/aei216

16. Daniels CE, Ryu JH (2011) Improving the safety of thoracentesis. Curr Opin Pulm Med. https://doi.org/10.1097/MCP.0b013e3283 45160b

17. Miraglia R, Maruzzelli L, Piazza M et al (2016) Real-time ultrasound-guided placement of a pigtail catheter in supine position for draining pleural effusion in pediatric patients who have undergone liver transplantation. J Clin Ultrasound. https://doi.org/10.1002/ jcu.22294

18. Broderick SR (2013) Hemothorax: etiology, diagnosis, and management. Thorac Surg Clin. https://doi.org/10.1016/j.thorsurg. 2012.10.003

19. Parry GW, Morgan WE, Salama FD (1996) Management of haemothorax. Ann R Coll Surg Engl 78(4):325-326.
20. Boersma WG, Stigt JA, Smit HJM (2010) Treatment of haemothorax. Respir Med. https://doi.org/10.1016/j.rmed.2010.08.006

21. Ruboff W (1995) Effectiveness of chest tube clamping in massive hemothorax. J Emerg Med. https://doi.org/10.1016/0736-4679(95) 98109-w

22. Ali J, Qi W (1995) Effectiveness of chest tube clamping in massive hemothorax. J Trauma. https://doi.org/10.1097/00005373199501000-00017

23. Bauman ZM, Kulvatunyou N, Joseph B et al (2018) A prospective study of 7-year experience using percutaneous 14-French Pigtail Catheters for Traumatic Hemothorax/Hemopneumothorax at a Level-1 Trauma Center: Size Still Does Not Matter. World J Surg. https://doi.org/10.1007/s00268-017-4168-3

24. Kim SIL (2014) Bacterial infection after liver transplantation. World J Gastroenterol. https://doi.org/10.3748/wjg.v20.i20.6211

25. Samra SS, Samra NS, Jain A, Mehta V (2006) Video-assisted thoracic surgery for hemothorax following coronary artery bypass. Asian Cardiovasc Thorac Ann. https://doi.org/10.1177/02184 9230601400225

26. Landreneau RJ, Keenan RJ, Hazelrigg SR, Mack MJ, Naunheim KS (1996) Thoracoscopy for empyema and hemothorax. Chest. https://doi.org/10.1378/chest.109.1.18

27. Billeter AT, Druen D, Franklin GA, Smith JW, Wrightson W, Richardson JD (2013) Video-assisted thoracoscopy as an important tool for trauma surgeons: A systematic review. Langenbeck's Arch Sur. https://doi.org/10.1007/s00423-012-1016-7

28. Morales Uribe CH, Villegas Lanau MI, Petro Sánchez RD (2008) Best timing for thoracoscopic evacuation of retained post-traumatic hemothorax. Surg Endosc Other Interv Tech. https://doi. org/10.1007/s00464-007-9378-6

29. Kumar S, Rathi V, Rattan A, Chaudhary S, Agarwal N (2015) VATS versus intrapleural streptokinase: a prospective, randomized, controlled clinical trial for optimum treatment of posttraumatic Residual Hemothorax. Injury. https://doi.org/10.1016/j. injury.2015.02.028

Publisher's Note Springer Nature remains neutral with regard to jurisdictional claims in published maps and institutional affiliations. 